\title{
Cross sectional echocardiographic diagnosis of total anomalous pulmonary venous connection
}

\author{
JAMES C HUHTA, HOWARD P GUTGESELL, MICHAEL R NIHILL \\ From the Lillie Frank Abercrombie Section of Cardiology, Departments of Pediatrics, Baylor College of Medicine; \\ and Texas Children's Hospital, Houston, Texas, USA
}

SUMMARY Total anomalous pulmonary venous connection can be diagnosed by cross sectional echocardiography. Information is, however, lacking concerning the diagnostic accuracy of this imaging method and any factors which may influence it. To predict the pulmonary venous connection 463 patients with congenital heart disease who had angiographic confirmation were prospectively examined. Total anomalous pulmonary venous connection was present in $34(7 \%)$ patients and correctly detected in 33 ( $97 \%$ sensitivity). There were two false positive results ( $99 \%$ specificity). All 23 patients with atrial situs solitus with or without associated congenital heart defects were correctly detected. One false negative result occurred in a patient with right atrial isomerism and complex congenital heart disease with decreased pulmonary blood flow.

Diagnosis of the type of total anomalous pulmonary venous connection, including the site and other anatomical details, was analysed and was correct in 24 of $34(71 \%)$ patients. Errors included $(a)$ incorrect prediction of the site of total anomalous pulmonary venous connection in five patients with right atrial isomerism, atrioventricular canal defect, and pulmonary atresia, $(b)$ details of confluence interconnection in three of four patients with the mixed type of connection, $(c)$ undiagnosed pulmonary venous obstruction in three of the patients with right atrial isomerism, and $(d)$ failure to predict common pulmonary vein atresia in one patient.

Factors which were related to incorrect echocardiographic diagnosis were abnormal atrial situs, mixed total anomalous pulmonary venous connection, and associated congenital cardiac defects, whereas age, weight, sex, clinical condition, and time during the study were not related.

It is concluded that cross sectional echocardiography can be used to diagnose accurately total anomalous pulmonary venous connection. This method can be the definitive imaging and diagnostic method in symptomatic infants with total anomalous pulmonary venous connection who have atrial situs solitus, unifocal pulmonary venous connection, and no evidence of other major congenital cardiac defect.

Reports from several centres have shown that the diagnosis of total anomalous pulmonary venous connection can be made by cross sectional echocardiography. ${ }^{1-3}$ The sensitivity and specificity of this method in detecting total anomalous pulmonary venous connection in children with suspected congenital heart disease are unknown. Also lacking is information concerning the factors which influence the confidence of

Requests for reprints to Dr James C Huhta, Department of Pediatric Cardiology, Texas Children's Hospital, 6621 Fannin Street, Houston, Texas 77030, USA.

Accepted for publication 15 January 1985 this diagnosis by cross sectional echocardiography. Once total anomalous pulmonary venous connection is detected, a complete examination should be performed to exclude other associated congenital heart disease and to define the details of pulmonary venous connection. Because cross sectional echocardiography may potentially be the definitive diagnostic method for this abnormality, we prospectively predicted the pulmonary venous connection in 463 patients. The data were analysed to determine $(a)$ the predictive accuracy of cross sectional echocardiography in detecting total anomalous pulmonary venous connection and $(b)$ the limitations of cross sectional echocar- 
diography in assessing the details of total anomalous pulmonary venous connection in children with congenital heart disease.

\section{Patients and methods}

Between July 1982 and August 1983, 463 consecutive patients underwent cross sectional echocardiography in whom the presence of a pulmonary venous connection was unknown. All studies were performed with Advanced Technology Laboratories echocardiographic equipment (MK600 or 300LX) using either 3, 5 , or $7.5 \mathrm{MHz}$ transducers and most were performed and interpreted by a doctor. Multiple scanning approaches, including subcostal, parasternal, and suprasternal, were combined in order to visualise all of the pulmonary veins and predict the normal or abnormal connection of each pulmonary vein (Fig. 1). ${ }^{2}$ A complete segmental echocardiographic examination was performed as previously described, 4 and the atrial situs was determined using previously published techniques. ${ }^{56}$ Abnormal atrial situs was confirmed by the angiographic appearance of the atrial appendages or by the radiographic appearance of the bronchi ${ }^{7}$ in all patients and by necropsy in four. In this way the location of the morphologically left
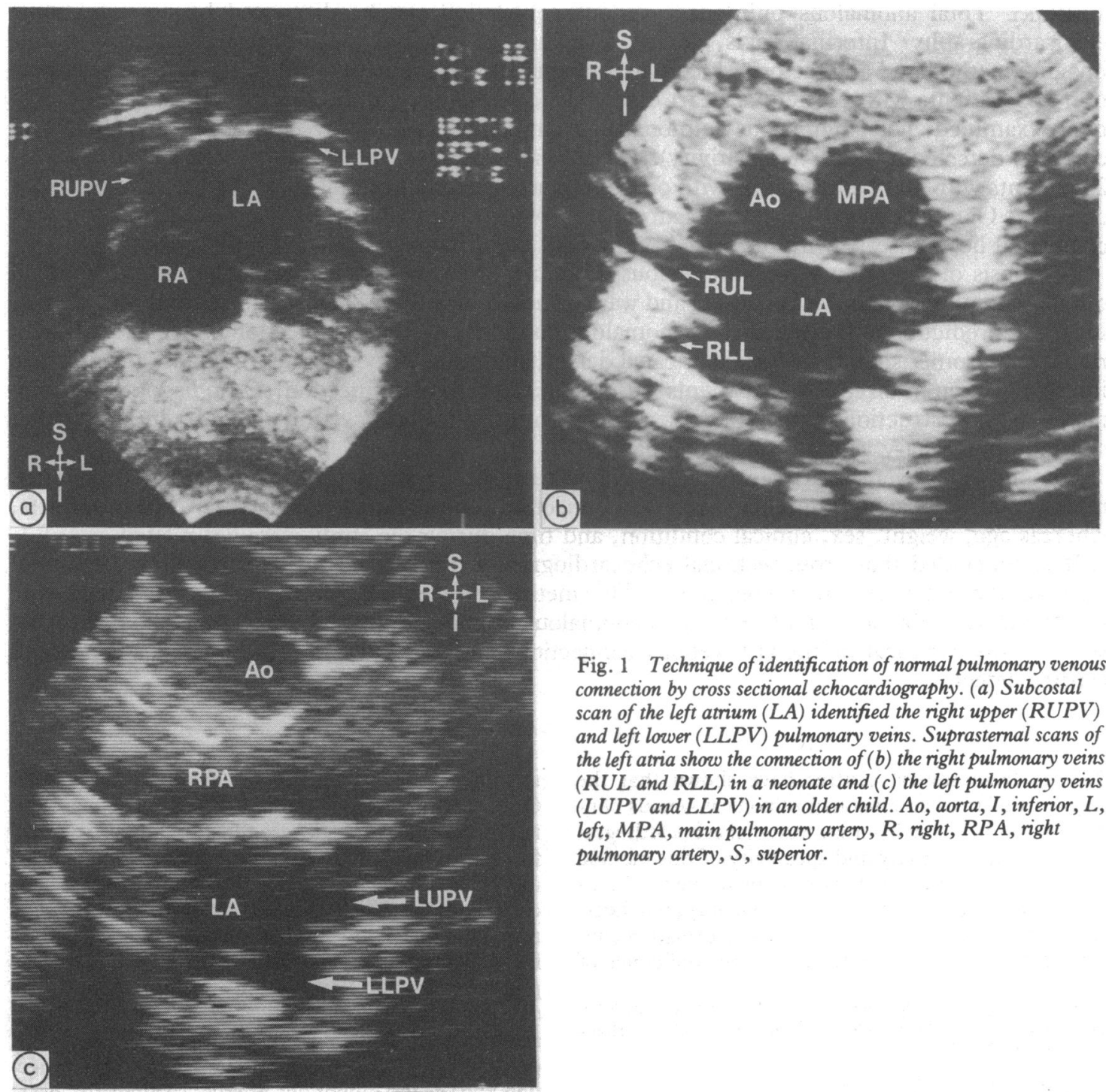

Fig. 1 Technique of identification of normal pulmonary venous connection by cross sectional echocardiography. (a) Subcostal scan of the left atrium (LA) identified the right upper (RUPV) and left lower (LLPV) pulmonary veins. Suprasternal scans of the left atria show the connection of $(b)$ the right pulmonary veins (RUL and RLL) in a neonate and (c) the left pulmonary veins (LUPV and LLPV) in an older child. Ao, aorta, $I$, inferior, $L$, left, MPA, main pulmonary artery, $R$, right, $R P A$, right pulmonary artery, $S$, superior. 
atrium (the expected site of normal pulmonary venous connection) was identified. In atrial situs solitus, normal pulmonary venous connection was defined as connection of all of the pulmonary veins to the left sided morphologically left atrium. Therefore, in situs solitus total anomalous pulmonary venous connection was excluded in the presence of at least one pulmonary vein connecting to the left sided atritm. Patients with partial anomalous pulmonary venous connection have a different presentation, their anomaly is associated with other congenital defects, and their morphological spectrum is different; these patients were included in the group of patients without total anomalous pulmonary venous connection and not analysed further. In patients with bilateral right atrial appendages (right atrial isomerism), in whom there is no morphological left atrium, all patients have total anomalous pulmonary venous connection to a pulmonary vein confluence which then may connect to either atria or to one of the systemic veins. In this situation even confluent connection to the left sided atrium is total anomalous connection and therefore these patients were included. During the study none of the patients with left isomerism had total anomalus pulmonary venous connection. Those with pulmonary venous connection to both atria were classified as having "partial" anomalous pulmonary venous connection.

Table 1 Details of patients with total anomalous pulmonary venous connection

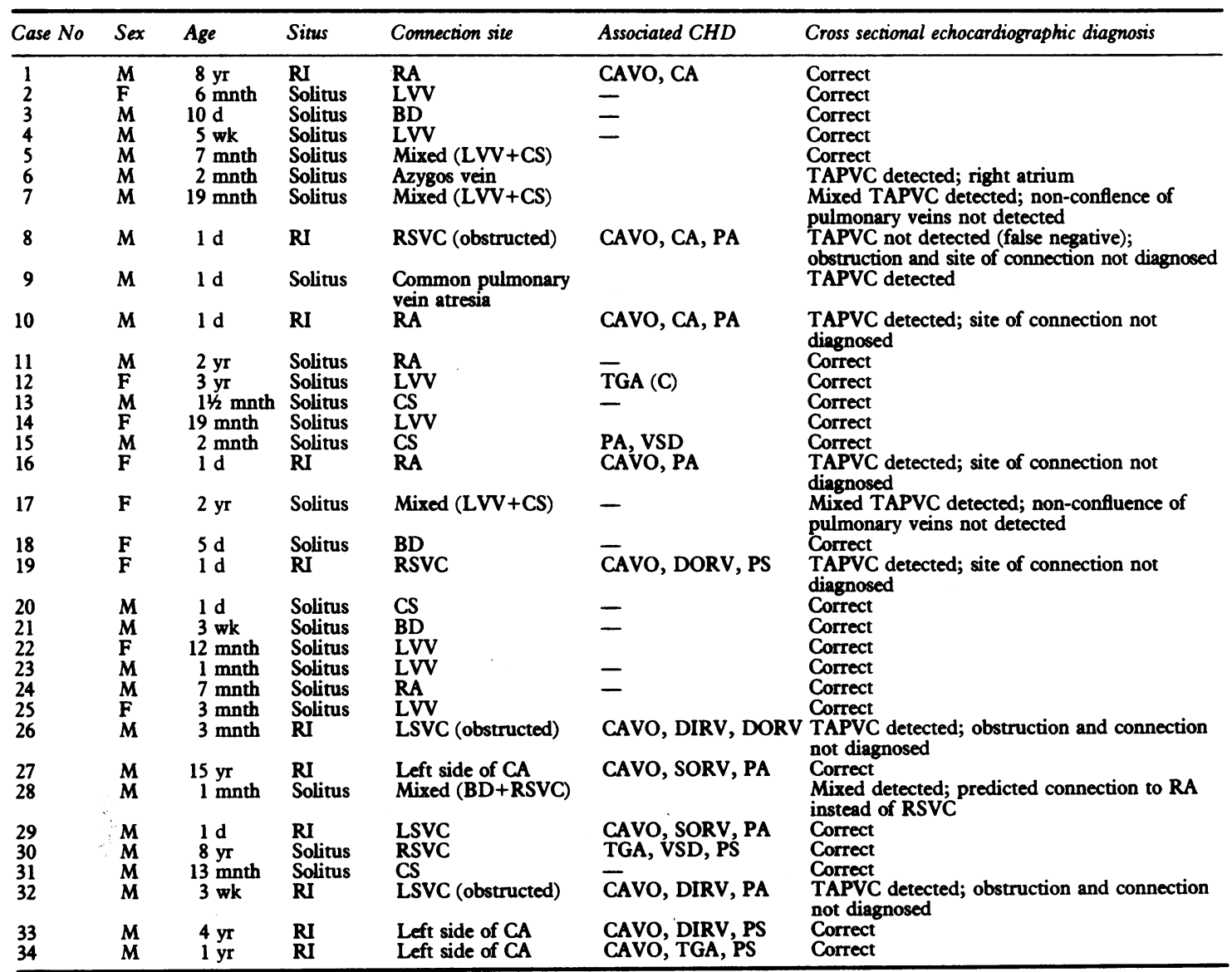

BD, below the diaphragm (obstructed); CA, common atrium; CAVO, common atrioventricular valve orifice; CHD, congenital heart disease; CS, coronary sinus; DIRV, double inlet right ventricle; DORV, double outlet right ventricle; $L S V C$, left superior vena cava; $L V V$, left vertical vein; PA, pulmonary atresia; PS, pulmonary stenosis; RA, morphological right atrium; RI, right atrial isomerism; RSVC, right superior vena cava; SORV, single outlet right ventricle; TAPVC, total anomalous pulmonary venous connection; TGA, transposition of the great arteries (ventriculoarterial discordance); TGA, (c) corrected transposition; VSD, ventricular septal defect. 
Table 2 Detection of total anomalous pulmonary venous connection by cross sectional echocardiography and angiography

\begin{tabular}{lllll}
\hline Angiography & \multicolumn{2}{l}{ Echocandiography } & & \\
\cline { 2 - 3 } & $\frac{\text { True }}{}$ & & False & \\
\cline { 2 - 3 } & + & - & + & - \\
\hline $\begin{array}{c}\text { True } \\
+\end{array}$ & 33 & 427 & 2 & 1 \\
\hline
\end{tabular}

+ , positive; - , negative.

Sensitivity $97 \%$, specificity $99 \%$.

The details of pulmonary venous connection by angiography were available in all patients, and the findings by cross sectional echocardiography were compared with the angiographic findings. Echocardiography was performed before any angiographic study in $\mathbf{3 8 0}$ patients and after in $\mathbf{8 3}$. All the echocardiographic examinations were performed without knowledge of this information in the latter group in an attempt to preserve the prospective aspect of echocardiographic prediction of pulmonary venous connection. The first cross sectional echocardiographic examination was analysed and the patients were excluded if the examiner was familiar with the diagnosis. Errors in detection of total anomalous pulmonary venous connection were expressed as false positive or false negative results and the sensitivity in detection was expressed as the number of true positive results divided by the sum of the true positive results plus the number of false negative results. Diagnostic errors were further analysed and factors affecting diagnostic accuracy assessed. The group of patients with any diagnostic error was compared with the other patients with total anomalous pulmonary venous connection in whom diagnosis was entirely accurate. Discrete variables such as sex or presence of abnormal situs were compared with $\chi^{2}$ methods. Linear variables such as weight and age were tested by
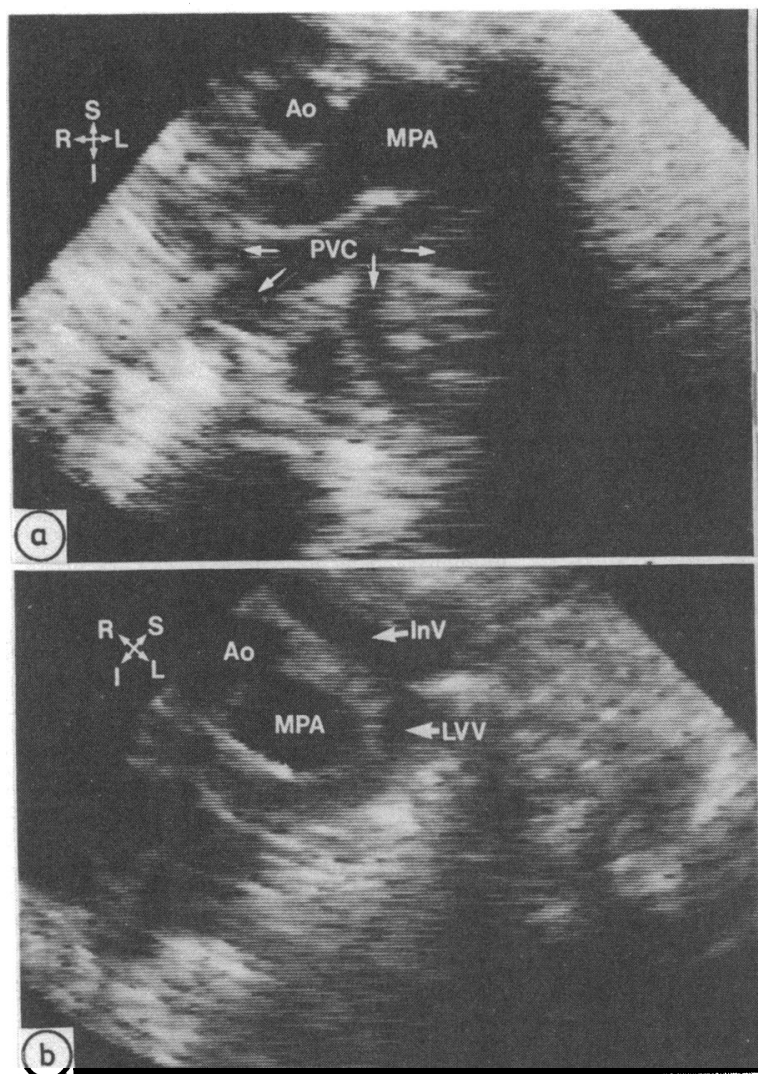

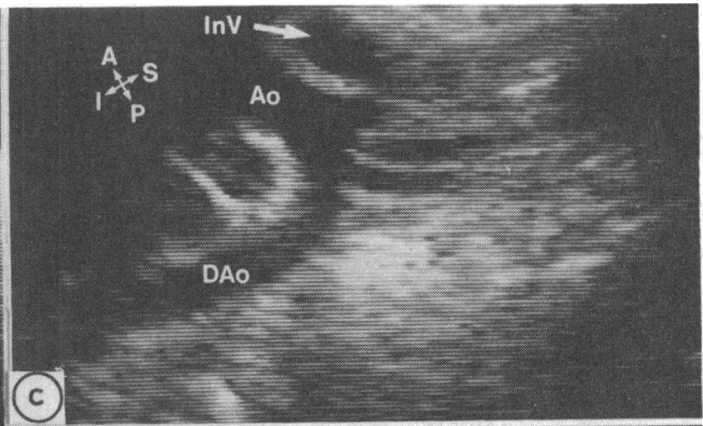

Fig 2 Segmental approach to the diggnosis of total anomalous pulmonary venous connection to a left vertical vein. Cross sectional echocardiograms showing (a) the four pulmonary veins (white arrows) connecting to a pulmonary venous confluence (PVC) in a suprasternal scan and $(b)$ and $(c)$ the left vertical vein $(L V V)$ and innominate vein $(\operatorname{InV})$ dilatation during counterclockwise rotation of the transducer; note the dilatation of the main pulmonary artery (MPA) compared with the aorta (Ao). (d) An angiogram is shown for comparison. A, anterior, DAo, descending aorta, $P$, posterior. Other abbreviations as in Fig. 1 . 

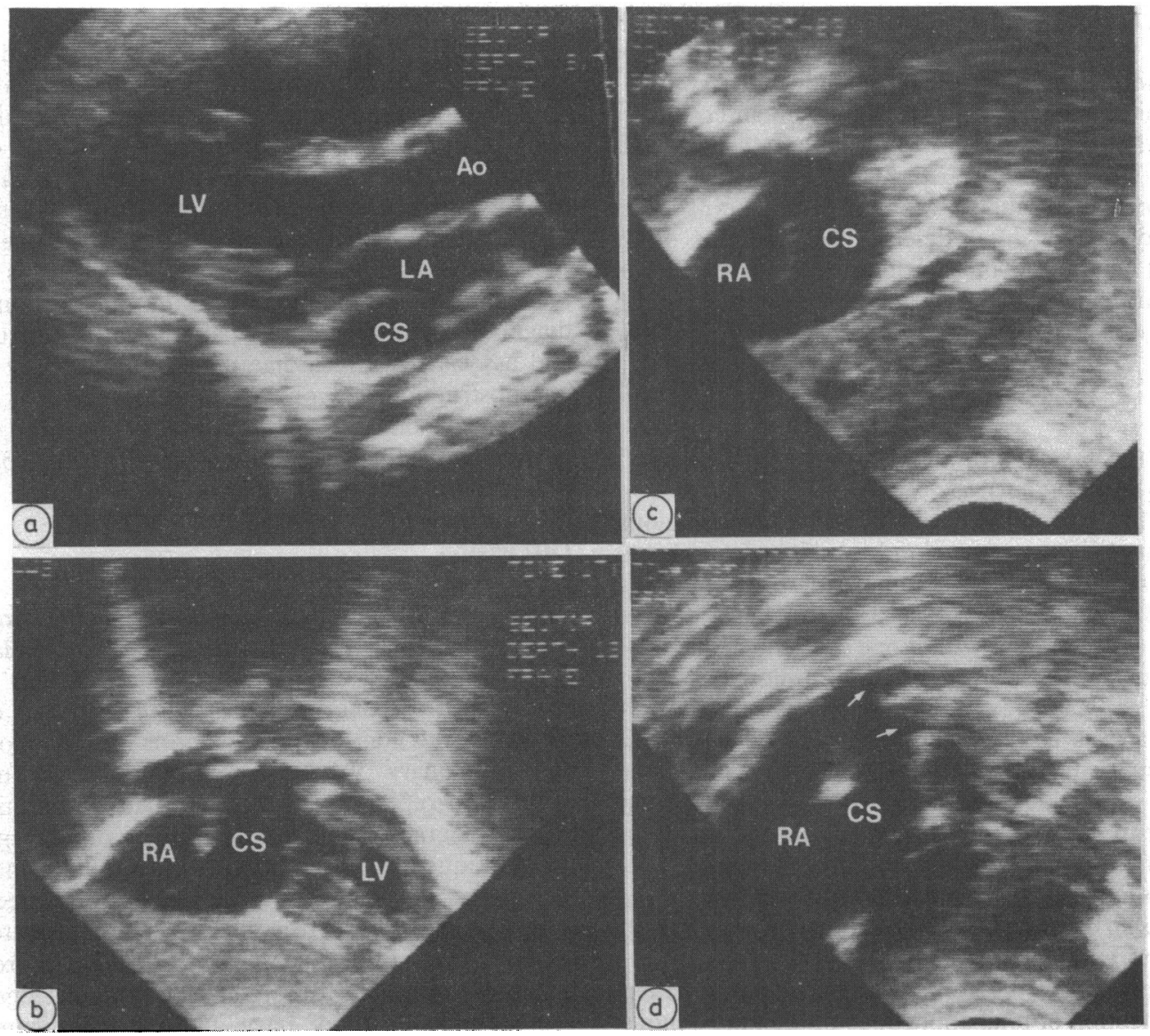

Fig. 3 Cross sectional echocardiograms showing total anomalous pulmonary venous connection to the coronary sinus. (a) The parasternal long axix scan shows a dilated coronary sinus (CS) and normal left heart structures. (b) $-(d)$. The subcostal scans confirm the normal coronary sinus connection to the right atrium $(R A)$ and the connection of the lefi pulmonary veins to the pulmonary venous confluence (white arrows). Abbreviations as in Figs. 1 and 2.
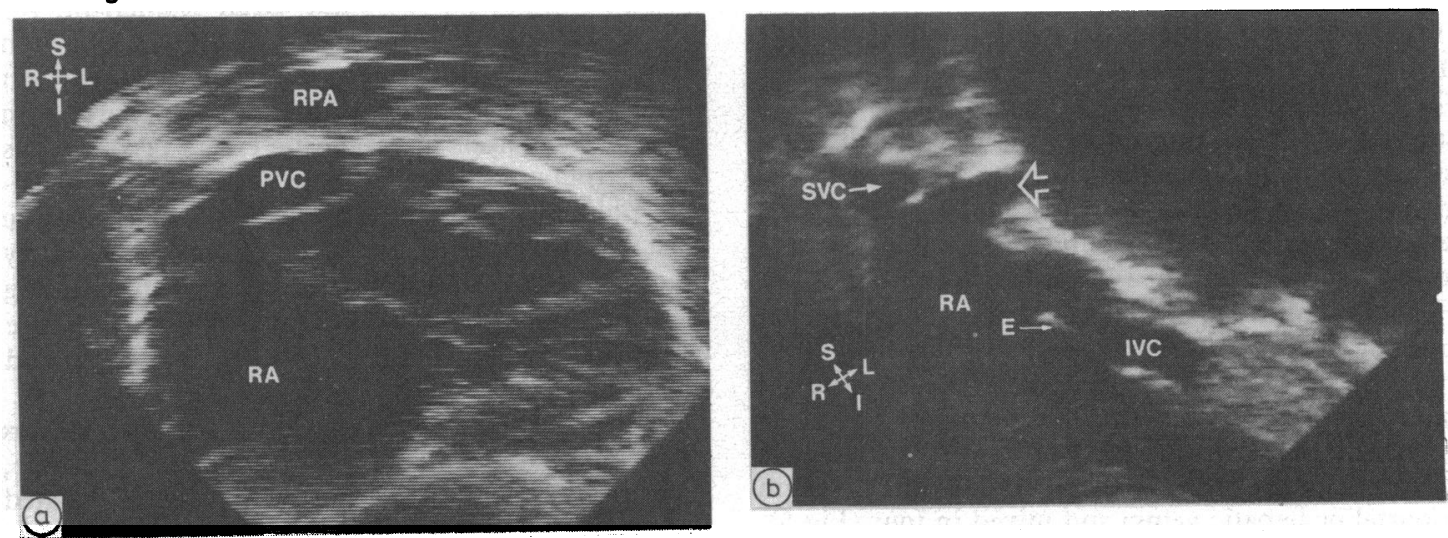

Fig. 4 Cross sectional echocardiograms showing total anomalous pulmonary venous connection to the right atrium $(R A)$. (a) The pulmonary venous confluence (PVC) is seen connecting to the right atrium from a subcostal scan; it was important to identify the more anterior right pulmonary artery (RPA) to make this diagnosis. (b) The site of pulmonary venous connection is visualised (open arrow) in a saggital plane from a subcostal scan and a large eustachian valve $(E)$ is seen. The superior $(S V C)$ and inferior $(I V C)$ venae cavae are seen connecting to the right atrium. Abbreviations as in Fig. 1. 
comparing the two groups with Student's $t$ test. Any variable with a $p$ value $<0.05$ was considered to be significant: Factors analysed included sex, weight, age, clinical status (ventilator dependent and critically ill scored 1 , others 0 ), type of pulmonary venous connection (supracardiac, cardiac, or infracardiac), atrial situs (normal or abnormal), and presence of other intracardiac congenital defects. Because this study spanned a period of 14 months with the possibility of a learning curve, the first and second seven month periods were compared.

\section{Results}

DETECTION OF TOTAL ANOMALOUS PULMONARY VENOUS CONNECTION

Of the 463 patients, $34(7 \%)$ had total anomalous pulmonary venous connection by angiography (Table 1). The sensitivity of detection of these patients was $\mathbf{9 7 \%}$ and the specificity was $\mathbf{9 9 \%}$ (two false positive results) (Table 2). In the one patient with total anomalous pulmonary venous connection that was not detected early in the study there was coexisting pulmonary atresia and low pulmonary blood flow with right isomerism and asplenia. False positive diagnoses of total anomalous pulmonary venous connection occurred in two patients: one was a neonate with an atrioventricular canal defect, pulmonary atresia, normally connecting veins, and atrial situs solitus and the other was an older infant with an unusually large atrial defect and a large coronary sinus.

The appearance of the intracardiac anatomy aided in the detection of total anomalous pulmonary venous connection. In situs solitus after the neonatal period, a typical pattern of intracardiac anatomy was found consisting of right heart dilatation and a relatively small left atrium and left ventricle.

\section{TYPE OF TOTAL ANOMALOUS PULMONARY \\ VENOUS CONNECTION (TABLE 1)}

The connection of all four pulmonary veins and the subtype of total anomalous pulmonary venous connection plus all other intracardiac and extracardiac anatomy were defined correctly in 24 of 34 (71\%) patients. Total anomalous pulmonary venous connection was supracardiac in 14: left vertical vein in seven (Fig. 2), right superior vena cava in three, left superior vena cava in three, azygos vein in one. There was intracardiac connection in 12: coronary sinus in four (Fig. 3), right atrium in five (Fig. 4), and left atrium in three with right isomerism. Infracardiac connection was present in three (below the diaphragm to portal or hepatic veins) and mixed in four (Fig 5). One patient had common pulmonary vein atresia.

There were three factors which related to diagnostic errors: presence of complex congenital heart disease with atrial isomerism (Fig. 6), mixed type of total anomalous pulmonary venous connection, and pulmonary vein atresia. Other factors such as the sites of anomalous pulmonary venous connection did not affect the accuracy of diagnosis. Presence of other congenital cardiac defects and presence of atrial isomerism were covariate owing to the frequent association of atrioventricular canal defect and severe pulmonary stenosis or pulmonary atresia with this situs abnormality. The pulmonary venous connection was diagnosed correctly in three patients with situs solitus and associated intracardiac defects. Pulmonary venous obstruction was present in three neonates with right atrial isomerism and was not diagnosed in spite of the neonatal use of prostaglandin $E_{1}$ before palliation of pulmonary atresia or stenosis.

\section{Discussion}

Anomalies of pulmonary venous connection are, in themselves, nearly always surgically remediable. They may be isolated or found in association with other types of congenital heart disease. After early reports of the non-invasive diagnosis of total anomalous pulmonary venous connection by $M$ mode echocardiography it was expected that cross sectional echocardiography would be a highly accurate diagnostic technique in this condition. ${ }^{8-10}$ Little information is, however, available concerning either the detection of this anomaly or the feasibility of complete anatomical assessment in such patients. Recently, improved echocardiographic equipment and knowledge of tomographic anatomy have allowed the diagnostic accuracy of cross sectional echocardiography in total anomalous pulmonary venous connection to be determined. This study also attempted to define factors which may hinder accurate diagnosis in this condition-namely, (a) right atrial isomerism, (b) mixed total anomalous pulmonary venous connection (most commonly to the coronary sinus and the left vertical vein), and (c) common pulmonary vein atresia. An analysis of diagnostic errors permitted us to construct a profile of the patient with total anomalous pulmonary venous connection who can be detected easily and whose anatomy can be accurately predicted. This information is valuable in assessing the need for surgical treatment of such infants in the newborn period and for diagnostic catheterisation and angiography.

In situs solitus the intracardiac anatomy was uniformly that of a dilated right atrium and ventricle, a relatively small left atrium and ventricle, dilated pulmonary annulus and proximal pulmonary arteries, and a restrictive atrial septal defect. By a combination of suprasternal and subcostal images, all four pulmonary veins were assessed and the mode of anomalous 


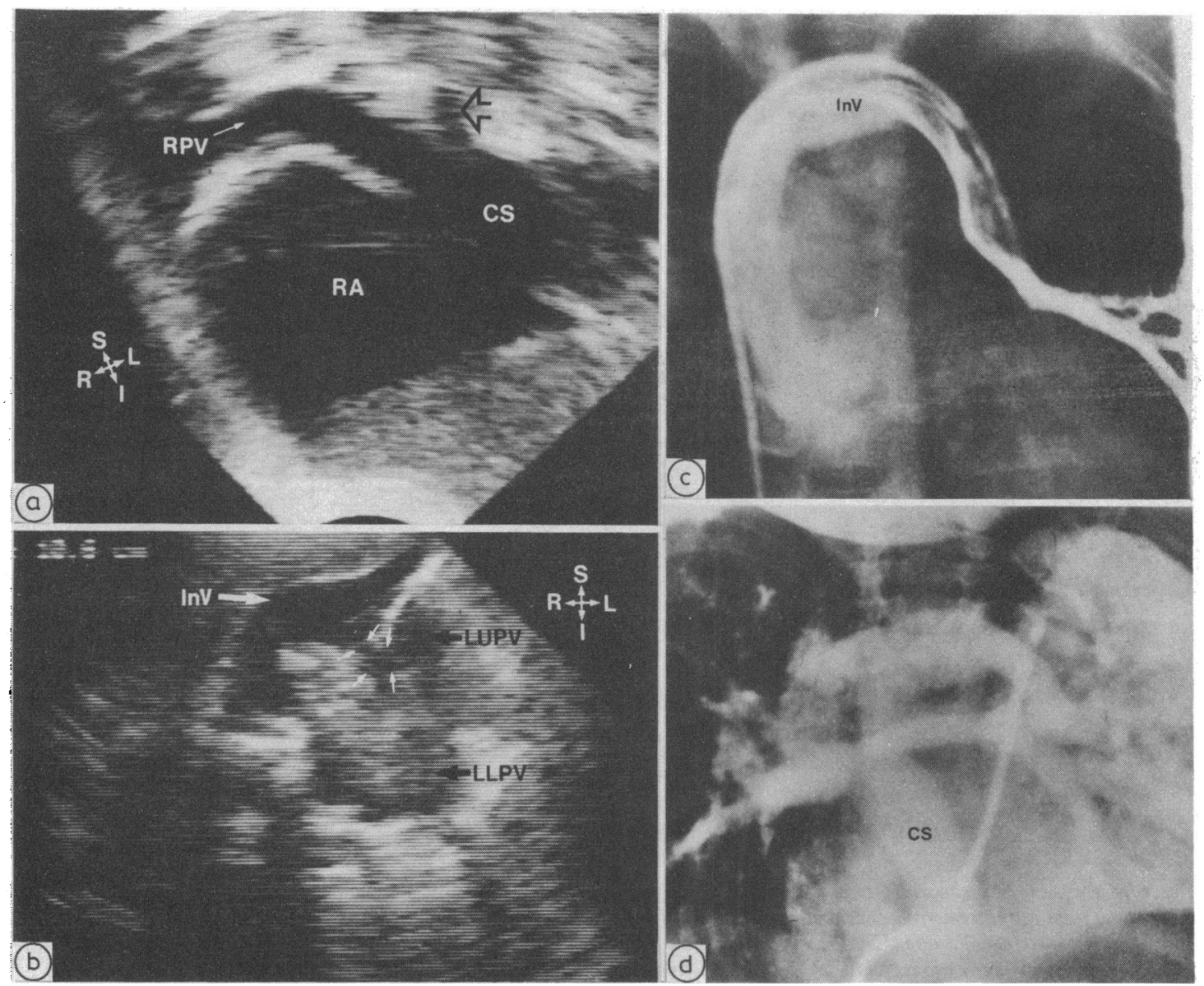

Fig. 5 Cross sectional echocardiograms $((a)$ and $(b))$ showing mixed total anomalous pulmonary venous connection to the corronary sinus (CS) and left vertical vein. (a) The right pulmonary veins (RPV) are identified from subcostal scans connecting to the coronary sinus and then to the right atrium (RA). Evidence of left pulmonary vein connection to the coronary sinus is also present (open black arrow). (b) A suprastermal scan shows the left upper pulmonary venous connection to a short left vertical vein (white arrows) and then the innominate vein (InV). (c) and (d) Angiograms of the same patient illustrate similar difficulty in defining the details of pulmonary venous connection of the mixed type. Injections were performed in the vertical vein $(c)$, and the pulmonary trunk (d) showed left pulmonary venous connection to two sites.

connection diagnosed. The limitations of cross sectional echocardiography in such patients were related to the sites of connection of the pulmonary venous confluences and interconnections of the pulmonary veins. Abnormalities of each of these factors were recognised by non-invasive assessment alone. False positive diagnosis of total anomalous pulmonary venous connection in situs solitus occurred in one patient with a large atrial septal defect and a left superior vena cava to the coronary sinus and in a neonate with situs solitus and asplenia.

The diagnosis of atrial situs can be made indirectly by cross sectional echocardiography by imaging the position of the inferior vena cava and aorta in relation to the spine at the level of the diaphragm. Specifically, right isomerism is nearly always associated with the aorta and inferior vena cava running together on one or other side of the spine. Because right isomerism has a high association with anomalous pulmonary venous connection and complex congenital heart disease with pulmonary stenosis or atresia, it is important to know the limitations of non-invasive diagnosis in these patients. We found that the site of pulmonary venous connection could not be consistently identified in the presence of low pulmonary blood flow. Furthermore, the frequent association of pulmonary venous obstruction could not be reliably predicted by imaging alone before construction of a systemic to pulmonary 


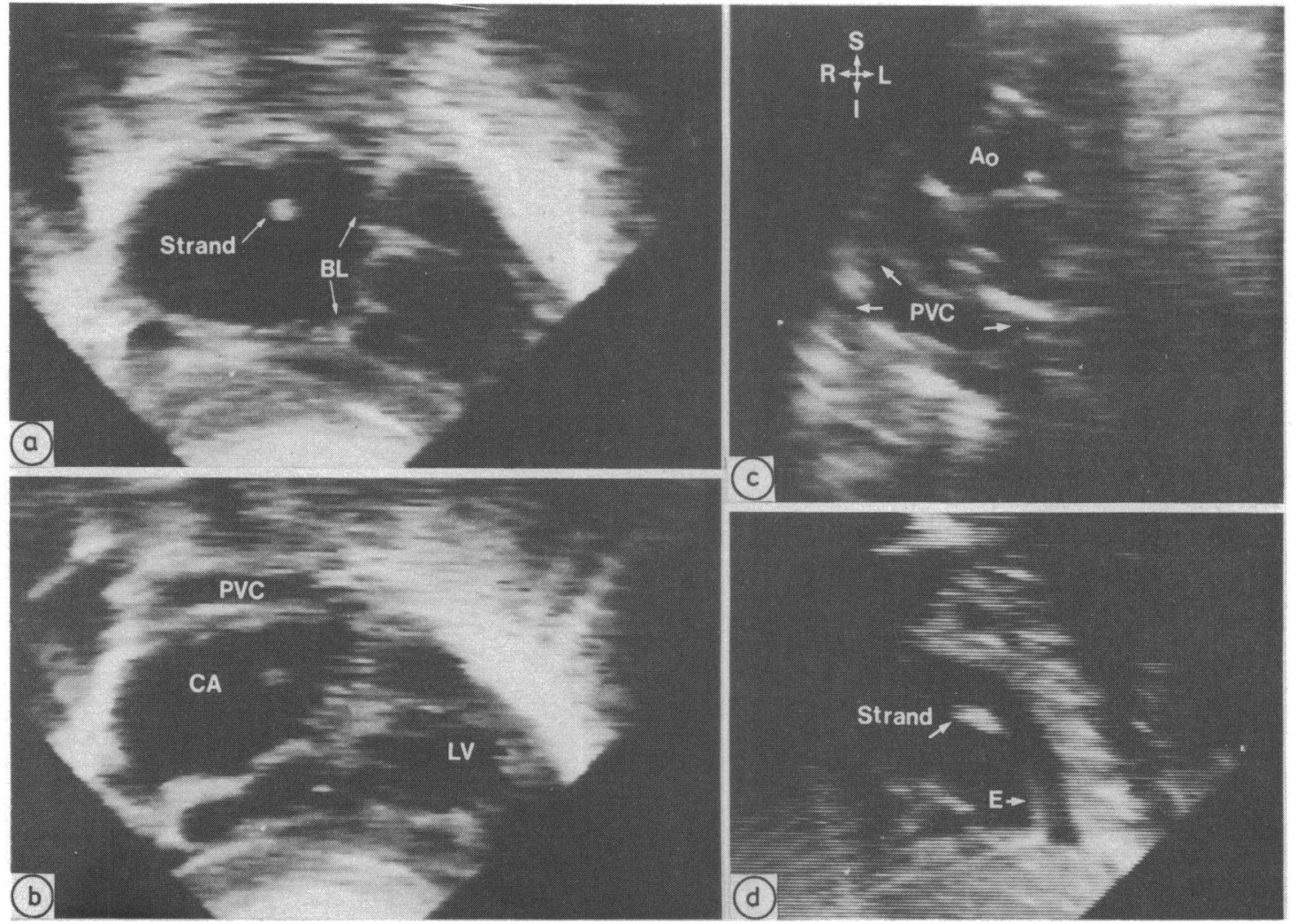

Fig. 6 Cross sectional echocardiograms showing total anomalous pulmonary venous connection to a posterior confluence (PVC) in an infant with right atrial isomerism. The presence of bilateral right atria is suggested by the presence of an atrial strand (a), the appearance of a common atrium (CA) (b), and a complete atrioventricular canal defect. The location of the confluence and the pulmonary veins connecting to it (white arrows) were defined from suprasternal scans (c). The relation of the atrial strand to the eustachian valve $(E)$ is shown in $(d)$. Note that the site of connection of the confluence is not defined nor is the presence of pulmonary vein obstruction.

shunt. Almost invariably the failure to identify the site of pulmonary venous connection meant pulmonary venous obstruction. Application of the prostaglandin challenge ${ }^{11}$ in the early neonatal period in four such patients failed to show the presence of pulmonary venous obstruction in three who later (3-4 months) died of congestive heart failure after construction of a systemic to pulmonary artery shunt. In the future it is likely that improved knowledge of the dynamics of pulmonary venous flow in total anomalous pulmonary venous connection using Doppler echocardiography 12 will improve detection of this important problem (Fig. 7). In one patient with right atrial isomerism Doppler echocardiography located the pulmonary venous connection to the right superior vena cava, and there was a good correlation between the echocardiographic and angiographic findings retrospectively (Fig. 8).

Mixed total anomalous pulmonary venous connec- tion was present in four patients, all with situs solitus, and there was associated congenital heart disease in one. All were shown to have total anomalous pulmonary venous connection; however, the details of mixed total anomalous pulmonary venous connection were difficult to identify in three patients. Two had pulmonary venous connection to the coronary sinus and the left vertical vein. In this setting, the pulmonary veins may or may not be in continuity, and this anatomical detail will affect the surgical approach. When they are in continuity, the surgical repair consists of using the connection to the coronary sinus and ligating the left vertical vein. When not in continuity, the veins from the left lung to the left vertical vein may be anastomosed to the left atrial appendage ${ }^{13}$ or directly to the left atrium. With our current policy at this hospital of using palliation by early balloon atrial septostomy and later blade/balloon atrial septostomy we have avoided early surgical repair of total anomal- 


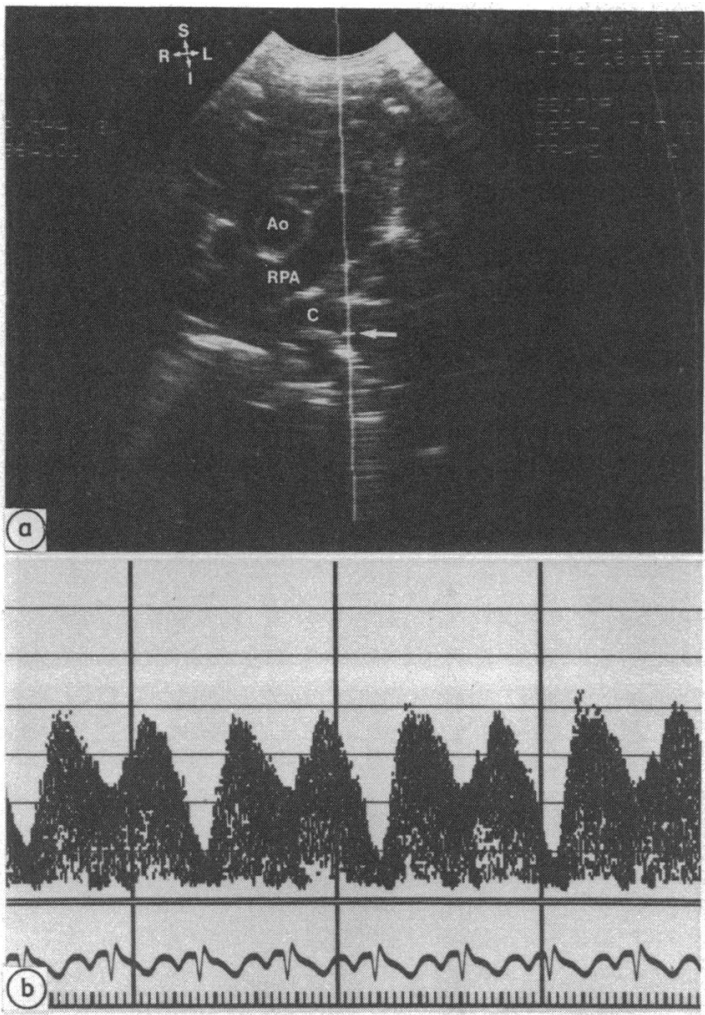

Fig. 7 (a) Cross sectional echocardiogram and (b) Doppler echocardiogram showing flow velocity in the pulmonary vein confluence $(C)$ in a 2 month old infant with total anomalous pulmonary venous connection to the coronary sinus. Note the low velocity signals (peak of $62 \mathrm{~cm} / \mathrm{s}$ ) at the site of Doppler sampling ((a) white arrow). Abbreviations as in Fig. 1.

ous pulmonary venous connection in many such patients. This may be important in those in whom a widely patent venous anastomotic channel could be more easily created for the anomalous veins at an older age. The important diagnostic result of this study was the finding that mixed total anomalous pulmonary venous connection could be detected accurately using suprasternal scans. ${ }^{14}$

One patient with common pulmonary vein atresia was found to have anomalous pulmonary venous connection, but the site could not be imaged. At angiography and necropsy the pulmonary veins drained via dilated bronchial veins. This anomaly is extremely difficult to diagnose, ${ }^{15}$ and such patients require angiographic study for a definitive diagnosis.

We conclude that cross sectional echocardiography can be used to diagnose accurately total anomalous pulmonary venous connection. This method can be the definitive imaging and diagnostic method in symptomatic infants with total anomalous pulmonary venous connection who have atrial situs solitus, unifocal pulmonary venous connection, and no evidence of other major congenital cardiac defect.

This study was presented in part at the cardiology section of the American Academy of Pediatrics, San Francisco, California in 1983. The work was supported in part by a grant from the National Institutes of Health, United States Public Health Service. JCH is supported in part by a grant from General Clinical Research Branch, National Institutes of Health, and is a recipient of a New Investigator Research Award from the National Heart, Lung, and Blood Institute, National Institute of Health, Public Health Service, Bethesda, Maryland, USA.

\section{References}

1 Sahn DJ, Allen HD, Lange LW, Goldberg SJ. Crosssectional echocardiographic diagnosis of the sites of total anomalous pulmonary venous drainage. Circulation 1979; 60: 1317-25.

2 Smallhorn JF, Sutherland GR, Tommasini G, Hunter S, Anderson RH, Macartney FJ. Assessment of total anomalous pulmonary venous connection by twodimensional echocardiography. Br Heart $\mathcal{F}$ 1981; 46: 613-23.

3 Snider AR, Silverman NH, Turley K, Ebert PA. Evaluation of infradiaphragmatic total anomalous pulmonary venous connection with two-dimensional echocardiography. Circulation 1982; 66: 1129-32.

4 Huhta JD, Smallhorn JF, Macartney FJ. Two dimensional echocardiographic diagnosis of situs. Br Heart $\mathcal{f}$ 1982; 48: 97-108.

5 Tajik AJ, Seward JB, Hagler DJ, Mair DD, Lie JT. Two dimensional real-time ultrasonic imaging of the heart and great vessels. Technique, image orientation, structure identification, and validation. Mayo Clin Proc 1978; 53: 271-303.

6 Huhta JC, Hagler DJ, Seward JB, Tajik AJ, Julsrud PR, Ritter DG. Two-dimensional echocardiographic assessment of dextrocardia: a segmental approach. Am $\mathcal{f}$ Cardiol 1982; 50: 1351-60.

7 Partridge JB, Scott O, Deverall PB, Macartney FJ. Visualization and measurement of the main bronchi by tomography as an objective indicator of thoracic situs in congenital heart disease. Circulation 1975; 51: 188-96.

8 Tajik AJ, Gau GT, Schattenberg TT. Echocardiogram in total anomalous pulmonary venous drainage. Mayo Clin Proc 1972; 47: 247-50.

9 Glaser J, Whitman V, Liebman J. The differential diagnosis of total anomalous pulmonary venous drainage in infancy by echocardiography [Abstract]. Circulation 1972; 46 (suppl II): 38.

10 Paquet M, Gutgesell H. Echocardiographic features of total anomalous pulmonary venous connection. Circulation 1975; 51: 599-605.

11 Freedom RM, Olley PM, Coceani F, Rowe RD, The prostaglandin challenge. Test to unmask obstructed total 

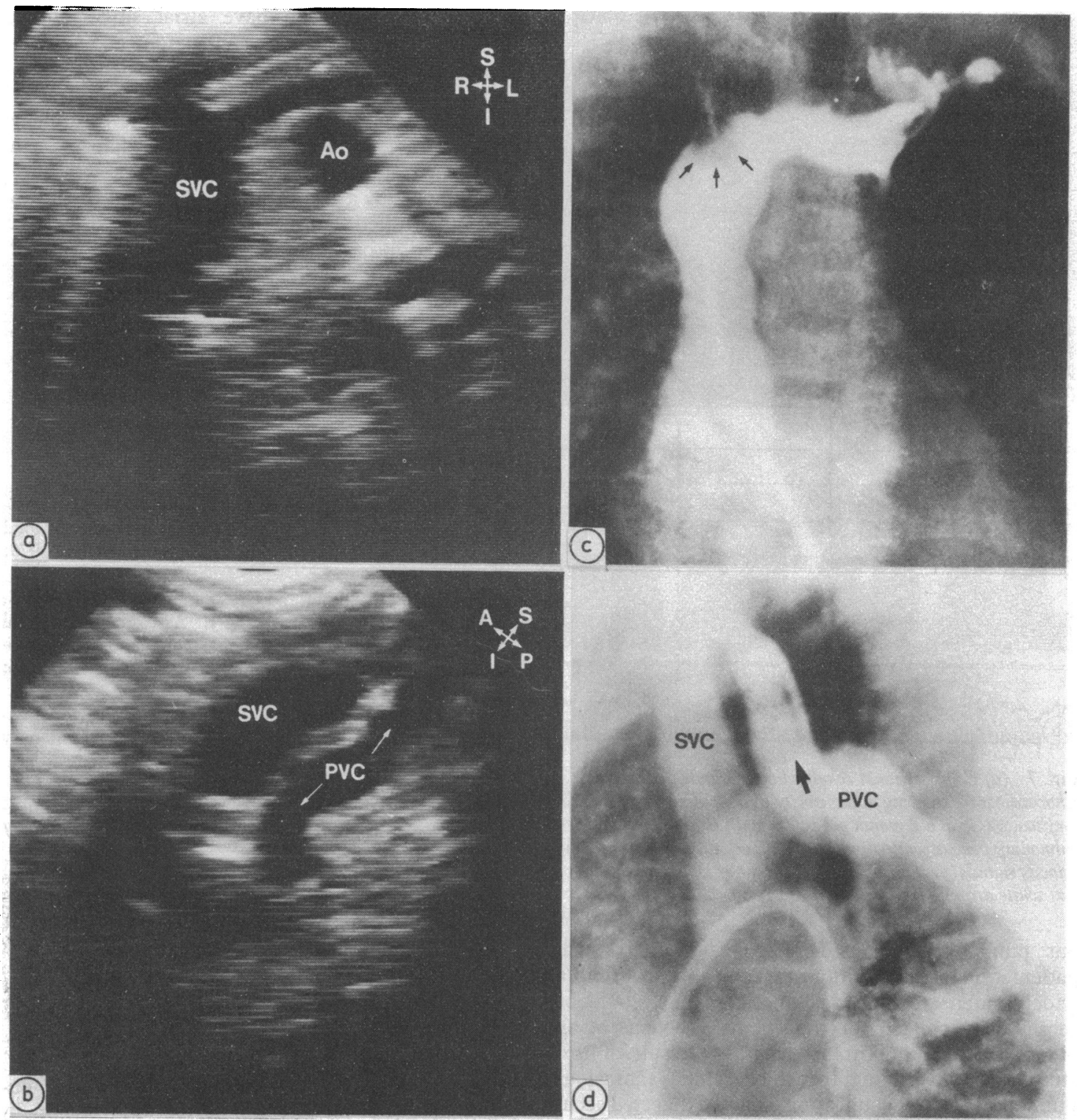

Fig. 8 ((a) and (b)) Cross sectional echocardiograms and ((c) and (d)) angiograms showing complex pulmonary venous connection to the right upper superior vena cava (SVC). (a) In suprasternal scans this structure was dilated, suggesting that this was the site of confluence connection and the angiogram (c) confirmed this; note washout of SVC (black arrows). (b) A saggital parasternal scan and corresponding angiogram (d) show the unusual course of the pulmonary venous confluence. Abbreviations as in Figs. 1 and 2.

anomalous pulmonary venous connections in asplenia syndrome. Br Heart $\mathcal{F}$ 1978; 40: 91-4.

12 Skovránek J, Túma S, Urbancová D, Šamánek M. Range-gated pulsed Doppler echocardiographic diagnosis of supracardiac total anomalous pulmonary venous drainage. Circulation 1980; 61: 841-7.

13 de Leval M, Stark J, Waterston DJ. Mixed type of total anomalous pulmonary venous drainage. Surgical correction in three infants. Ann Thorac Surg 1973; 16: 464-70.
14 Sahn DJ, Goldberg SJ, Allen HD, Canale JM. Crosssectional echocardiographic imaging of supracardiac total anomalous pulmonary venous drainage to a vertical vein in a patient with Holt-Oram syndrome. Chest 1981; 79: 113-5.

15 Khonsari S, Saunders PW, Lees MH, Starr A. Common pulmonary vein atresia. Importance of immediate recognition and surgical intervention. $\mathcal{f}$ Thorac Cardiovasc Surg 1982; 83: 443-8. 